\title{
PARAMETRIC ARRAYS IN AIR WITH APPLICATIONS TO ATMOSPHERIC SOUNDING
}

\author{
T.G. Muir and M. Vestrheim \\ Applied Research Laboratories, The University of Texas at Austin, P.0. Box 8029 \\ Austin, Texas 78712 USA
}

Résumé. - On étudie les propriétés et les possibilités d'application d'antennes paramétriques à faisceau étroit se propageant dans l'air. En ce quỉ concerne la description du champ sonore à faible intensité (variation du niveau de pression et de la réponse azimuthale en fonction de la distance) .on généralise les résuitats précédemment obtenus en tenant compte de la self-démodulation du régime transitoire et des effets provenant de la saturation des primaires à haute intensitê. On ëtudie également les effets propres aux expériences rẻalisēes dans l'atmosphère : variation diurne de température, d'humidité et par conséquent d'absorption. Enfin les possibilités d'application des antennes paramétriques à la détection sonore dans l'atmosphẽre sont examinées. On trouve que les variations diurnes ne causent pas de grandes difficultés. Par contre un problème non trivial se pose dans le cas d'applications requérant une source à haute intensité. Des solutions de ce problème sont suggërées.

Abstract. - Theoretical and experimental results are presented to demonstrate the character and utility of narrow beam parametric arrays operating in air. Beginning with the delineation of the field at low intensities (variation of pressure level and azimuthal response with increasing range) we expand previous work to include the self-demodulation of transients and high-intensity effects associated with acoustic saturation of the primary radiations. Effects peculiar to experiments in the atmosphere are also presented, such as the diurnal variation of temperature, humidity, and consequently absorption. Practical applications associated with the use of parametric arrays in atmospheric sounding are examined from the feasibility standpoint. It is concluted that normal diurnal variations pose no great difficulties, while the low parametric efficiency poses a nontrivial problem for applications requiring high source levels. Solutions to this problem are suggested.

1. Introduction.- Since its discovery in 1960 (1), the parametric array has been researched and developed predominantly in underwater acoustics. Only a few papers dealing with experiments in air have appeared in the archival 1iterature $(2-5)$. The not application of parametric arrays to air acoustics problems has been received with skepticism (6).

The purpose of the present paper is to expand the present knowledge of parametric experiments in air with a view toward assesing the potential of possible practical applications.

The parametric array generates a narrow, lowfrequency sound beam with no side lobes through the nonlinear interaction of intense high-frequency radiations emitted from a small primary sound source. Three general types of parametric arrays have been identified and discussed in some detail (7). Each has its own characteristics and special theoretical models. Their distinction is based on the relative size and shape of the interaction region.

\section{Experimental illustration of a parametric} acoustic field. - As in any acoustic experiment, the transducer is usually of primary. importance. NonJinear acoustics requires intense radiation, which normally leads to a peak pulse power demand at the expense of a low duty cycle. Applications in air are further influenced by practical emphasis on 1) reasonable efficiency, 2) wide bandwidth, 3) good impedance coupling, and 4) low internal distortion.

The transducer used has a $5.7 \mathrm{~cm}$ diameter face consisting of 7 clamped plate resonators whose center frequency is displaced from that of the mass-loaded ceramic driver. The primary radiations are launched at the two resonances. Figure 1 illustrates the $0.56 \mathrm{~m} \mathrm{f/2}$ parabolic reflector mounted on a two axis rotator column, as well as a microphone and its supporting $6 \mathrm{~m}$ tower. (The face of the transducer is turned away from the reflector in this figure). The tower rides on a car rolling on a $250 \mathrm{~m}$ railway. A double FM radio link relays received signals for analysis as a function of range $r$ from the source.

This equipement was used in a purely exploratory approach to air acoustics applications, with no particular detection or sensing requirements imposed. The resulting data of Figs. 2 and 3 demonstrate the acoustic field of primary and secondary radiations acquired in the course of some measurements in a dead calm atmosphere at $25^{\circ} \mathrm{C}$ and $77 \%$ relative humidity. The primaries were transmitted with an acoustic power on the order of 1 Watt. It 


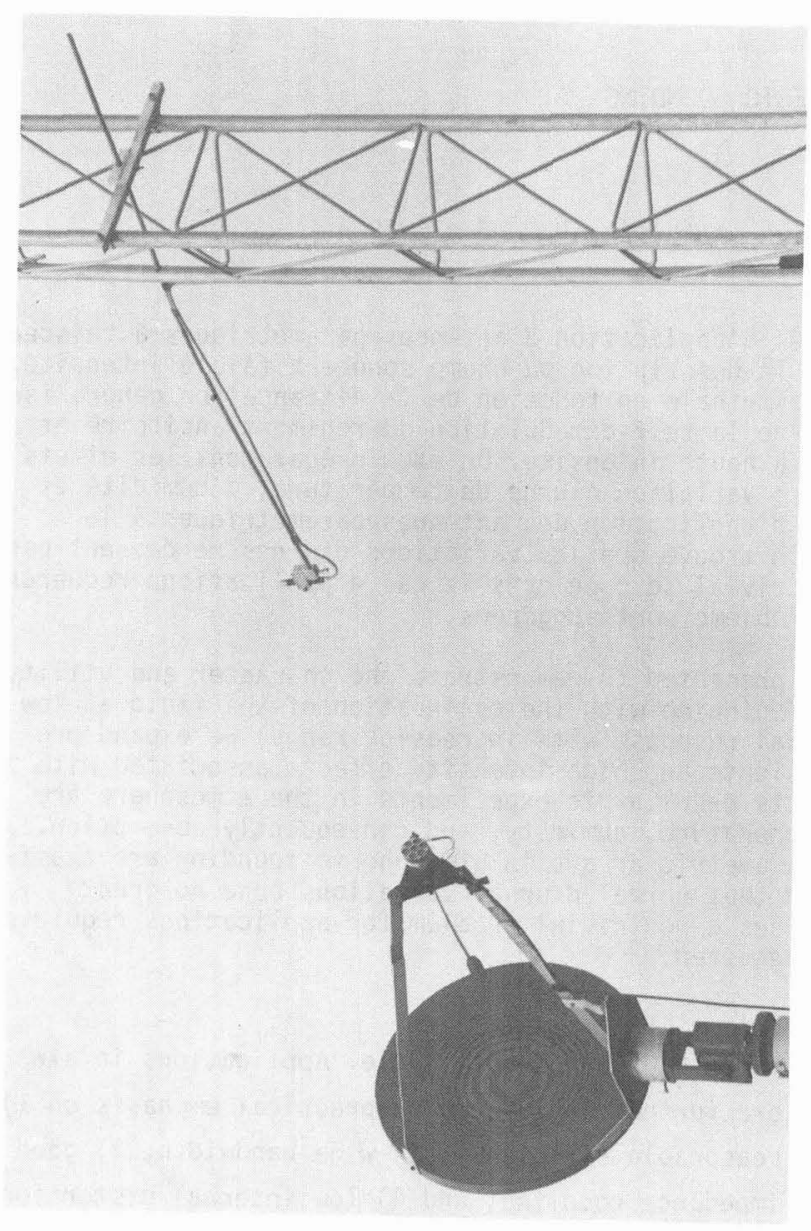

Fig. 1 : The experimental arrangement for propagation measurements.

can be seen that the transducer beam is somewhat larger than predicted, giving the reflector an effective diameter of $0.34 \mathrm{~m}$.

The far-field parametric pressure is modeled by the Westervelt formula (1). Good agreement between theory and experiment is shown in Fig. 3 for the sound pressure level of the $1 \mathrm{kHz}$ difference frequency radiation. It can be seen that the experimental spot size is somewhat smaller than the predicted value. It is also about 6 times smaller than that which could be radiated linearly from the same effective aperture at the same $1 \mathrm{kHz}$ frequency.

3. Atmospheric sounding. Remarkable advances in the use of acoustics to probe the atmosphere have been made since $1968(6)$. Amongst the practical applications realized to date are profiling of the planetary boundary layer to study air mass inversions, the subsistence of inversion layers, mixing,

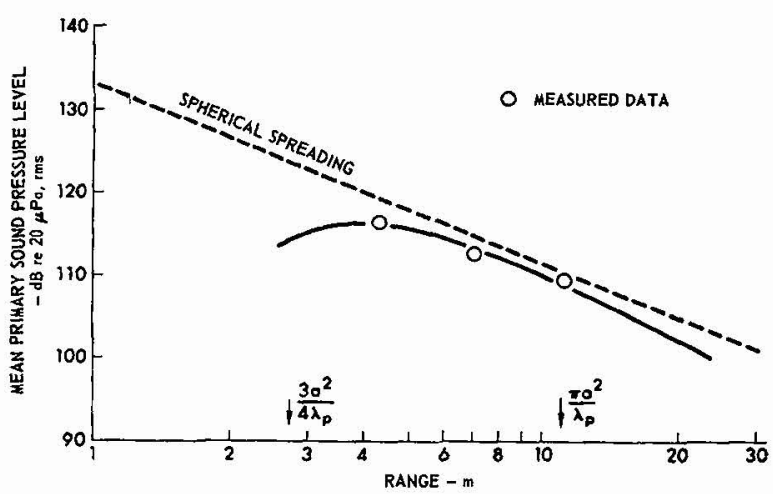

(o)

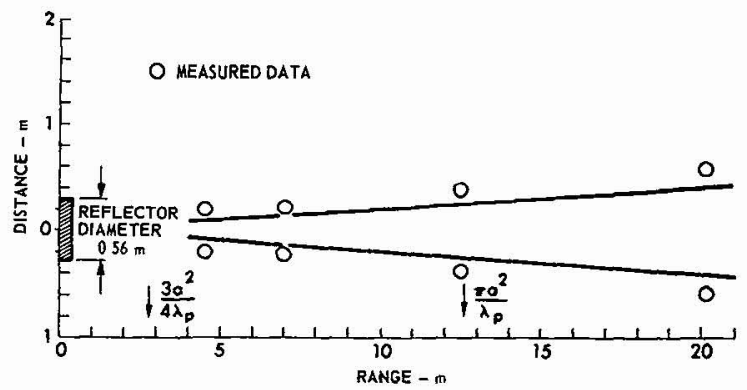

(b)

Fig. 2 : The acoustic field of primary radiations a) propagation curve, b) half-power spot size of the beam.

thermal plumes, and gravity (internal) waves. These studies are quite significant in the air pollution and meteorologic disciplines. Also important are practical applications to Doppler sensing of wind speed, vertical profiling of wind velocity, the measurement of wind shear and the development of sensors for shear induced turbulence. These devices have been developed and tested for use at airports, as have combination acoustic and electromagnetic sensors which are also amenable to aircraft applications for the detection of clear air turbulence.

The attractiveness of acoustic sensors lies in the fact that the acoustic cross section for turbulence is some $10^{6}$ times greater than that for electromagnetic waves (6). It is predominantly the temperature differentials in the turbulent atmosphere that influence the acoustic cross section.

Atmospheric sounders can be deployed in several configurations (6). Simple monostatic sounders are usually mounted on a vertical axis and are operated like a depth sounding sonar to probe the atmosphere on the basis of echo amplitude. This configuration is modeled by the echosonde equation (8), 


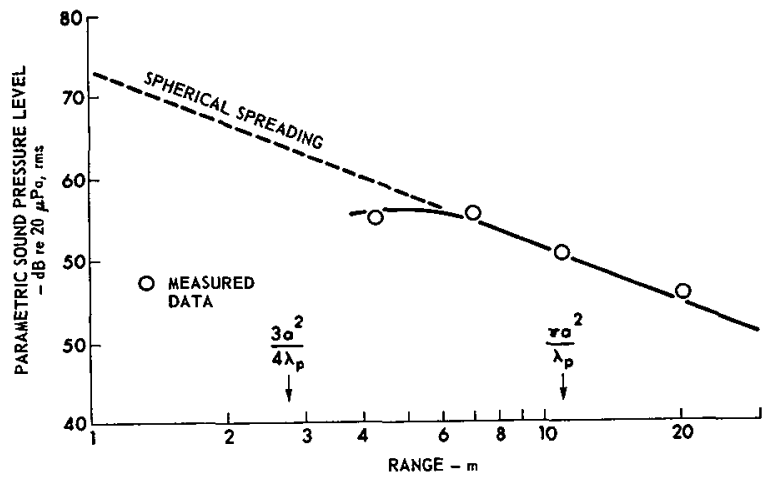

(a)

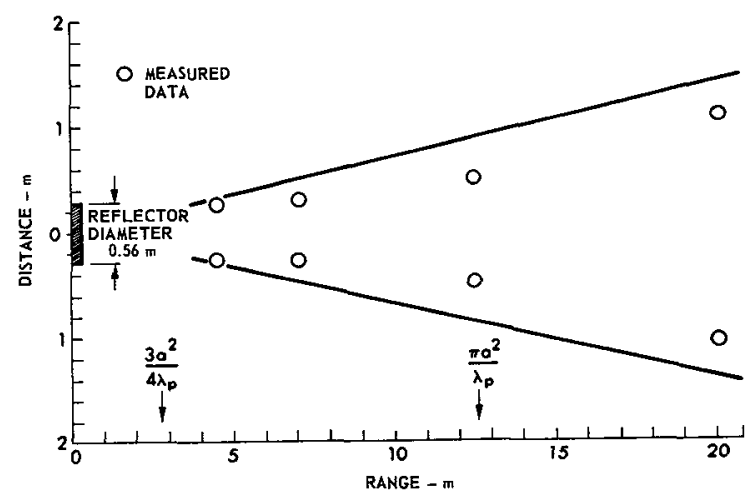

(b)

Fig. 3 : The acoustic field of difference frequency radiation, a) propagation curve, b) half-power spot size of the beam.

$P_{R}=P_{T} e^{-2 \alpha R}\left[{ }^{\sigma_{0}}(R, f) \quad\left(\frac{C_{O} \tau}{2}\right)\left(\frac{A}{R^{2}}\right) G\right]$,

where the received power $P_{R}$, transmitted power $P_{T}$, range $R$, pulselength $\tau$, aperture area $A$ are straightforward parameters. The effective aperture factor $G$ arises from the transducer directivity. The acoustic cross section $\sigma_{0}$ is frequently approximated (9) by

$$
\sigma_{0}=0.0039 k^{1 / 3} \frac{c_{t}^{2}}{T_{0}}
$$

where $k$ is the wave number, $T_{0}$ the mean temperatu$r e$, and $\mathrm{C}_{t}{ }^{2}$ is the temperature structure parameter, which frequently varies from $10^{-3}$ to $10^{-4}$.

Several models have been developed for Doppler sensing of wind fields, ranging from the simple monostatic case to those involving three- dimensional triangulation $(6,8)$.

4. Applicability of parametric sources. As in any analysis there are advantages and disadvantages with each alternate approach. The quite attractive parametric radiation patterns, generated from small apertures, warrant a consideration of the nonlinear approach to atmospheric sounding. This is appropriate and timely as side lobe reflections from terrestrial features have recently been identified as sources of false structures in sounder records (10). other potential advantages of parametric sounders exist.

The diurnal variations in ambient temperature and humidity affect the absorption and consequently the properties of the parametric array. Some typical values are plotted in Fig. 4. Over the range

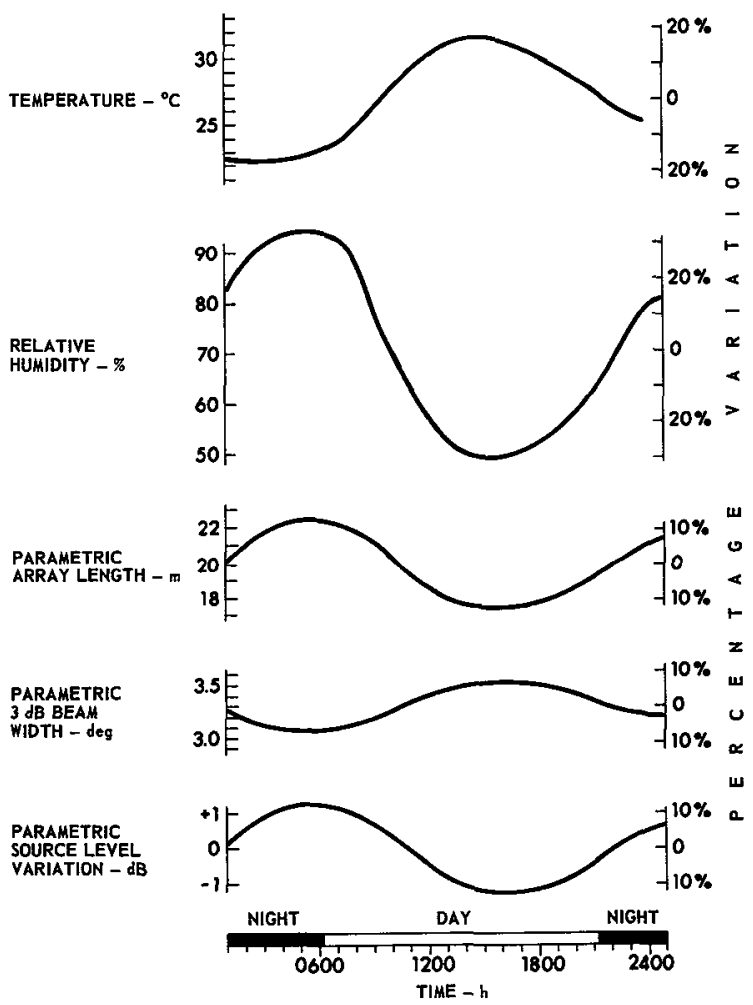

Fig. 4 : Diurnal variations in parametric array properties over a typical summer day in Texas.

of values shown, the night time decrease in temperature and increase in humidity increases the parametric array length, $L_{A}=1 /\left(2 \alpha_{0}\right)$, and decreases the half-power beamwidth, $\theta_{3 \mathrm{~dB}}=4\left(\alpha_{0} / \mathrm{k}_{\mathrm{s}}\right)^{1 / 2}$, while the effective source level is simuttaneousty increased. Since the 24 hour variation in array 
length only spans $\pm 13 \%$, the beam width $\pm 7 \%$, and the source level $\pm 12 \%$, the diurnal effects do not appear significant, especially since they can be accounted for. This may be more difficult in periods of transition from calm to violent weather, or for use of the same array one day in a rain forest, the next on a desert.

Perhaps a more serious concern is the relative inefficiency of parametric arrays and their consequent low source level. This usually restricts parametric applications to problems where the low efficiency is not an issue, such as ocean depth sounding and propagation is shallow water. The efficiency issue is not trivial for applications to atmospheric sounding.

For purposes of discussion, we can consider source level requirements for an existing wind shear sounder deployed at Dulles International Airport in Washungton D.C. by the National Oceanic and Atmospheric Administration, Wave Propagation Laboratory. The main transmitter of this system radiates 120 Watts in a $9^{\circ}$ half-power beam at $1250 \mathrm{~Hz}$ from a parabolic horn, $2 \mathrm{~m}$ in diameter. The extrapolated source level is approximately $157 \mathrm{~dB}$ re $20 \mu \mathrm{Pa}$ rms at $1 \mathrm{~m}$. Although it would be ludicrous to seriously compare this system to the simple experiment illustrated in the present paper, since it radiates less than a watt (at the primary frequencies), the frequencies are nonetheless similar while the beamwidth and source diameter of the experiment are about 2 to 3 times smaller, respectively.

The question of increased radiated power now arises. There are limits to arbitrary increases as the primaries eventually go into shock which means harmonic generation, increased absorption, and eventual acoustic saturation. A useful model for a largely plane wave parametric array in shock has been discussed in reference 11 , and results concerning the parametric source level for the present experiment are shown in Fig. 5. It can be seen that although the slope of the amplitude response curve changes from quadratic to linear in the shock region, the amplitude of the difference frequency radiation continues to increase with increase in primary power. This is accompanied by an increase in parametric beamwidth, (11) and simply means that acoustic saturation ultimately limits the attainable source levels, array lengths, and beamwidths (12).

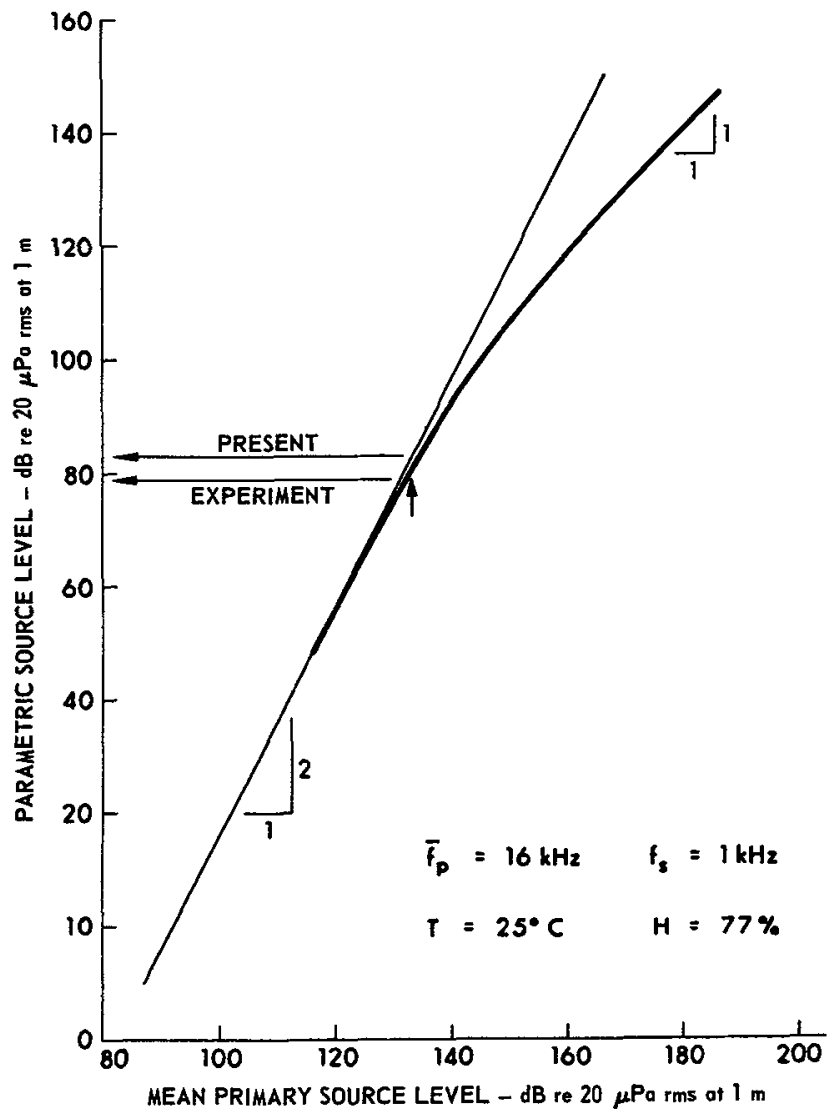

Fig. 5 : High amplitude response of the parametric array experiment.

5. - Self-demodulation of transients. The transmission of an intense $\mathrm{cW}$ puise is accompanied by the interaction of its sideband components to produce a directive parametric transient of low frequency content. The original model (13) predicting this effect was derived for the axial pressure response in the time domain. It shows a dependence on the second time derivative of the square of the primary pulse envelope function $f\left(t-x / c_{0}\right)$, in the form

$p_{t}(x, t)=\frac{p_{0}^{2} s_{0}(1+\gamma)}{32 \pi \rho_{0} c_{0}^{4} \alpha_{0} x} \quad \frac{\partial^{2}}{\partial t^{2}}\left[f\left(t-\frac{x}{c_{0}}\right)\right]^{2}$

Experimental verification of this effect in liquids has been published (14).

The question arises as to the existence and potential utility of the self-demodulation transient in air. The axial time domain data of Fig. 6 


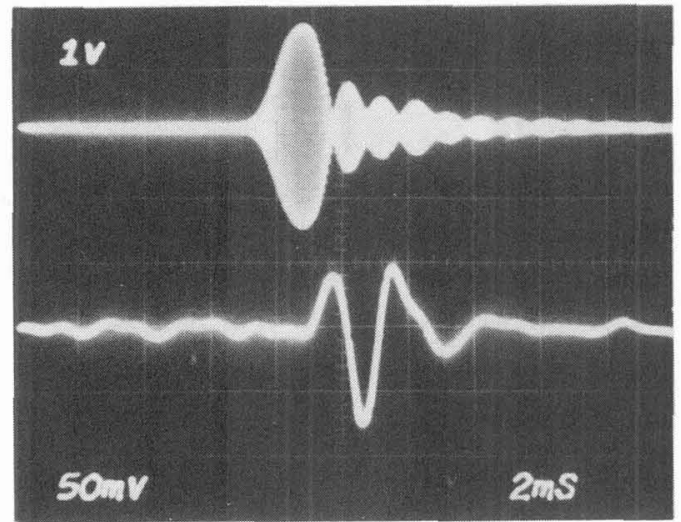

Fig. 6 : Experimental demonstration of the selfdemodulation effect in air. Top trace : primary pulse; bottom trace : self-demodulation transient.

was acquired during the course of the present measurements to illustrate the effect. A dual beam oscilloscope was used to depict both the primary and demodulated signals resulting from transmission of an $18 \mathrm{kHz}$ pulse at a range of $9.3 \mathrm{~m}$. The difference in arrival times for these two signals is due to the geometry of the frequency selective receiver.

It can be seen that a demodulated transient was here obtained, in reasonable consonance with theory, despite the low power level of the present experiment. Systems producing hundreds of watts of radiated pulse power should be expected to generate fairly strong self-demodulation transients in the medium. Their bandwidths can be made quite large, with frequency responses extending down to the infrasonic region. Their directivity at these frequencies could be remarkably high. It is suggested that existing sounders be examined for this effect.

Also of potential interest is the application of directive parametric transients to turbulence research. Use of the parametric transient would appear to lead instantaneous wideband sensing through impulse response techniques. Other possibilities exist.

6.- Conclusions. The nature of parametric arrays in the atmosphere has been examined with theory and experiment. Practical applications have been suggested and considered from the feasibility standpoint. It was shown that diurnal variations in temperature pose no great problems in parametric array generation. The low efficiency and source level of this process is nontrivial. Applications requiring high source levels should employ spherically diverging primaries to circumvent the limiting effects of acoustic saturation within the interaction volume. The generation of directive, low requency transients through the self-demodulation of primary pulses was identified as a viable process for air acoustics with possible implications for applications in infrasonics and turbulence research. Existing atmospheric sounders should be examined as sources of parametric transients.

7. - Acknowledgements. M. Vestrheim's contribution was made possible by the Royal Norwegian Council for Scientific and Industrial Research. T.G. Muir acknowledges helpful discussions with E.M. Brown, D.W. Beran, and W.D. Neff of the Wave Propagation Laboratory, National Oceanic and Atmospheric Administration, Boulder, Colorado, and with D.W. Thompson of the Pennsylvania State University and Risø National Laboratory, Copenhagen.

\section{References}

11/ Westervelt, P.J., J. Acoust. Soc. Am., 1963, 35,535 .

12/ Bellin, J.L.S., and Beyer, R.T., J. Acoust. Soc. Am., 1962, 34, 1051.

/3/ Brinkmann, K., Acustica, 1968, 20, 92.

14/ Bennett, M.B., and Blackstock, D.T., J, Acoust., Soc. Am., 1975, 57, 562.

/5/ Muir, T.G., in Finite-amplitude wave effects in fluids, proc. 5th ISNA (IPC Science and Technology Press, Ltd.) 1974, p. 119

16/ Brown, E.H., and Ha11, F.F., Rev. Géophys. and Space Phys., 1978, 16, 47.

17/ Vestrheim, M., in Finite-amplitude wave effects in fluids, proc. 5th ISNA (IPC Science and Technology Press, Ltd.) 1974, p. 140 .

18/ Hall, F.F., in Remote Sensing of the Troposphere, (U.S. Gov. Printing office, Washington, D.C.) 1972 , ch. 18.

19/ Neff, W.D., in Proc. 15iri Radar Meteorology Conf., (Amer. Meteor. Soc. Boston) 1975, p. 263.

/10/ Brown, E.H., Little, C.G., and Wright, W.M. J. Acoust. Soc. Am. 1978, 63, 694.

111/ Bartram, J.F., J. Acoust. Soc. Am., 1972 , 52, 1042 .

112/ Shooter, J.A., Muir, T.G., and Blackstock, D.T., J. Acoust. Soc. Am., 1974, 55, 54. 
C8- 94

113/ Berktay, H.0., J. Sound Vib., 1965, 2 (4), 435.

114/ Moffett, M.B., Westerve7t, P.J., and Beyer, R.T., J. Acoust. Soc. Am., 1971, 49, 339. 